\title{
Expanding Intensive Care Unit Management for Critically Ill Patients During COVID-19 Pandemic
}

\section{COVID-19 Pandemisinde Kritik Hastaların Tedavisi için Yoğun Bakım Ünitelerinin Kapasite Artışı}

(D) Kerem Erkalp, (D) Mehmet Salih Sevdi, (D) Ali Özalp

Bağcılar Training and Research Hospital, Clinic of Anesthesiology and Reanimation, İstanbul, Turkey

\section{Dear Editor,}

The cumulative incidence of coronavirus disease (COVID-19) cases has also been increased in Turkey. In approximately $14 \%$ cases, COVID-19 develops into a more severe disease requiring hospitalization, while the remaining $6 \%$ of the cases experience critical illness requiring management in intensive care unit (ICU)s (1). Therefore, the demand for ICU beds has increased in İstanbul Bağcılar Training and Research Hospital.

In our hospital, anesthesiology and reanimation department has two ICUs including a level- III ICU with 20 beds ( 20 ventilators) and a level-II ICU with 11 beds (5 ventilators). In addition, there are only six isolation rooms in there.

In the middle of March, with the onset of the first cases, we started to use the ICU area with six-bed isolation rooms for suspected COVID-19 patients since the number of COVID-19 positive patients was low in the first place (Triage ICU). When the test results of the patients resulted as positive during their stay, we transferred the COVID19-positive patients to the three-bed isolation rooms in cardiovascular surgery (CVS) ICU in cooperation with the CVS clinic (Cohort ICU). Since patient hospitalization increased dramatically in a short period of time, we started to provide care to suspected COVID-19 patients by transferring the patients in the level III-ICU with 14 beds to the clinics, palliative care center, ICU at the department of general surgery and level II-ICU. Thus, isolated ICU areas were created for 14 COVID-19-suspected (Triage ICU) and nine COVID-19-positive patients (Cohort ICU). In addition, a level-III arena area with 14 beds of CVS-ICU and a level II-arena area with 13 beds ICU were turned into a 50-bed Cohort ICU with the ventilator that was re-supplied as a result of cooperation with the cardiology clinic and general surgery clinics (Figure 1). As in many countries, we might not have enough ICU beds, let alone isolation or single rooms, in the first place. With an executive attitude, all ICU areas were converted to areas that were negatively pressurized with respect to surrounding areas. In this regard, national and regional modeling is crucial for ICUs for patient and employee safety (2).

At the moment, it has been approximately the end of the first month since the pandemic started in Turkey. In the ICUs in our hospital, a total of 48 patients, 20 of which have been receiving non-invasive mechanical ventilation, have been treated. Before the pandemic, our department's ICU beds were $6.2 \%$ of the number of hospitalized patients while during these days, it increased to $14.9 \%$ thanks to the increase in the capacity. The increase in the bed numbers is not enough to expand the ICU capacity and it should be supported by the increase in the necessary equipment (i.e. 


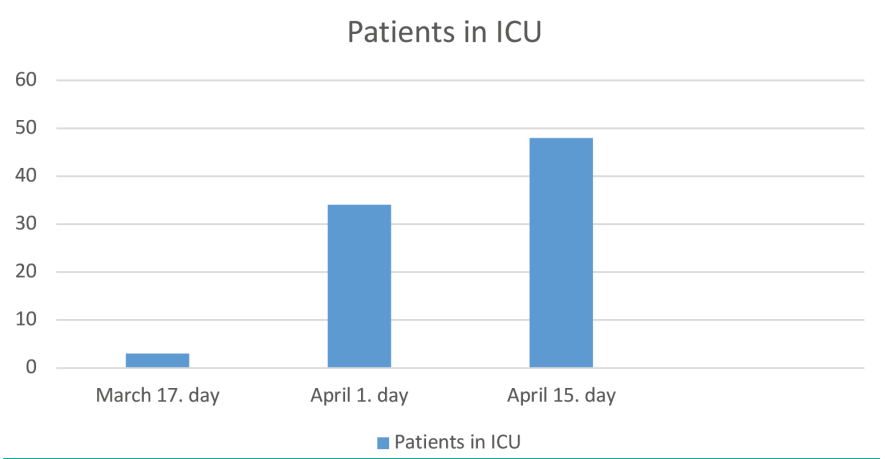

Figure 1. The number of patients in ICU in COVID-19 pandemic's first month period

ICU: Intensive care unit, COVID-19: Coronavirus disease

ventilators), consumables, pharmaceuticals, and staffing. Although focusing on bed numbers without ensuring the availability of necessary equipment is unsafe, such equipment might be in short supply. Even though one can suggest that increased number of beds should not be considered as safe as without being able to have essential equipment, such tools may become scarce. Requirement of use of transport, operating theatre, and military ventilators may arise (3). Moreover, we do not have any issues with the number of beds in the ICU with patients' turn over.

We will share the data regarding patients in the upcoming days.

Keywords: Bed capacity, COVID-19 pandemic, intensive care
Anahtar kelimeler: COVID-19 pandemisi, yatak kapasitesi, yoğun bakım

\section{Ethics}

Peer-review: Externally and internally peer-reviewed.

\section{Authorship Contributions}

Concept: K.E., M.S.S., A.Ö., Design: K.E., M.S.S., A.Ö., Data Collection or Processing: K.E., M.S.S., A.Ö., Analysis or Interpretation: K.E., M.S.S., A.Ö., Literature Search: K.E., M.S.S., A.Ö., Writing: K.E., M.S.S., A.Ö.

Conflict of Interest: No conflict of interest was declared by the authors.

Financial Disclosure: The authors declared that this study received no financial support.

\section{References}

1. Kinross P, Suetens C, Dias JG, Alexakis L, Wijermans A, Colzani E, et al. Rapidly increasing cumulative incidence of coronavirus disease (COVID-19) in the European Union/European Economic Area and the United Kingdom, 1 January to 15 March 2020. Euro Surveill 2020;25(11):2000285.

2. Phua J, Weng L, Ling L, Egi M, Lim CM, Vasishta J, et al. Intensive care management of coronavirus disease 2019 (COVID-19): challenges and recommendations. Lancet Respir Med 2020;6(20):3016130162.

3. Xie J, Tong Z, Guan X, Du B, Qiu H, Slutsky AS. Critical care crisis and some recommendations during the COVID-19 epidemic in China. Intensive Care Med 2020;46(5):837-840. 